\title{
The role of salicylic acid in the prevention of oxidative stress elicited by cadmium in soybean plants
}

\author{
Guillermo Noriega - Ethel Caggiano • Manuel López Lecube • Diego Santa Cruz • \\ Alcira Batlle $\cdot$ María Tomaro $\cdot$ Karina Beatriz Balestrasse
}

Received: 30 January 2012/ Accepted: 1 August 2012

(C) Springer Science+Business Media, LLC. 2012

\begin{abstract}
The protective action of salicylic acid (SA) pre-treatment on soybean plants before cadmium (Cd) addition was tested. Oxidative stress parameters, such as TBARS formation, glutathione and chlorophyll content, were altered by $\mathrm{Cd}$, instead no differences were observed in plants only pre-treated with SA. Antioxidant enzymes were affected by Cd treatment, while SA protected against these effects. These findings indicated that SA could act as a protector against oxidative stress induced by $\mathrm{Cd}$. Taking into account the fact that heme-oxygenase-1 (HO-1) has been previously described as a novel antioxidant enzyme, experiments were carried out to determine whether it was involved in the protection exerted by SA. As expected, Cd brought about an enhancement of $57 \%$ in HO-1 activity and $150 \%$ in protein content $(150 \%)$, SA also increased both the enzyme activity
\end{abstract}

G. Noriega - A. Batlle · M. Tomaro

Centro de Investigaciones sobre Porfirinas y Porfirias

(CIPYP), CONICET, Buenos Aires, Argentina

E. Caggiano - M. L. Lecube - D. S. Cruz ·

K. B. Balestrasse $(\square)$

Departamento de Química Biológica, Facultad de

Farmacia y Bioquímica, Universidad de Buenos Aires,

Junín 956, 1113 Buenos Aires, Argentina

e-mail: kbale@ffyb.uba.ar

\section{S. Cruz - K. B. Balestrasse}

Instituto de Investigaciones en Biociencias Agrícolas y

Ambientales (INBA), CONICET, Buenos Aires,

Argentina and its protein content ( 28 and $75 \%$, respectively). Surprisingly, the observed rise of $\mathrm{HO}$ activity and protein content under SA treatment was lower than that produced by $\mathrm{Cd}$ alone. These lower values indicated, that HO-1 could not be directly involved in the protection of SA against $\mathrm{Cd}$ effects. In order to shed light in the mechanisms involved in SA effects, Cd content was determined in the tissues of $\mathrm{Cd}$ treated plants with and without SA pre-treatment. Results indicated that, in the presence of SA, Cd uptake was inhibited, thus avoiding its deleterious effects. Moreover, the observed HO-1 activity enhancement by SA indicates that this phytohormone could be engaged in the signalling pathway of heme degradation.

Keywords Cadmium $\cdot$ Heme oxygenase $\cdot$ Oxidative stress $\cdot$ Salicylic acid $\cdot$ Soybean plants

\section{Introduction}

Cadmium (Cd) is a toxic trace pollutant for humans, animals and plants which enters the environment mainly from industrial processes and phosphate fertilizers and then is transferred to the food chain. This metal is easily taken up by plant roots and can be loaded into the xylem for its transport into leaves. A large number of studies have demonstrated its toxic effect on plant metabolism, such as decrease uptake of nutrient elements (Wagner 1993; Mc Laughlin et al. 1999; Järup and Åkesson 2009), changes in nitrogen 
metabolism (Popova et al. 2009), alterations in heme metabolism (Noriega et al. 2004), among others. The toxicity of $\mathrm{Cd}$ has been related with the increase of lipid peroxidation and alterations in the antioxidant system (Popova et al. 2009).

Cadmium promotes the accumulation of reactive oxygen species (ROS), causes severe damage to important cellular components, such as lipids, proteins, DNA, and RNA (Foyer et al. 1994), and leads to a decreased growth, roll and chlorosis of leaves, and root necroses (Schutzendubel et al. 2001). These ROS include superoxide radical, hydroxyl radical and hydrogen peroxide. Plants have evolved a complex antioxidant system (i.e., enzymatic and nonenzymatic detoxification mechanisms) for protecting potential cell injury against tissue dysfunction. The antioxidant enzymes, such as catalase (CAT), peroxidases (POD), superoxide dismutases (SOD), can scavenge different types of ROS.

Salicylic acid (SA) is an endogenous growth regulator of phenolic nature, which participates in physiological processes in plants, such as growth, photosynthesis, nitrate metabolism, ethylene production and flowering (Hayat et al. 2007). SA is also known to be involved in abiotic stress signalling, including plant response to heavy metals. SA pretreatment alleviates Cd toxicity; SA not only plays a key role in establishing and signalling a defense response against various pathogenic infections, but also plays an important role in mediating plant response to some abiotic stresses including salinity, temperature, UV radiation and heavy metal stress (Wang et al. 2011).

Salicylic acid is a phytohormone with ubiquitous distribution in plants; it plays an important role in the regulation of plant growth and development (Malamy et al. 1990; Durner et al. 1997; Horváth et al. 2007). Recent studies indicate that it also participates in the signalling of abiotic stresses. There is strong evidence that SA mediates the oxidative burst that precedes the hypersensitive response and the development of systemic acquired resistance. Previous studies have shown that SA conferred plant resistance to various abiotic stresses such as heat acclimation (Dat et al. 1998), chilling tolerance (Kang and Saltveit 2002), salinity stress (Gunes et al. 2007), and cadmium toxicity (Krantev et al. 2008). All these studies demonstrated that the majority of SA-regulated abiotic stresses in plants are involved in antioxidant responses, thus indicating that protection of plants from oxidative damage by SA is associated with an enhanced antioxidant system (Dat et al. 1998; Horváth et al. 2007).

Heme oxygenase (HO-1, EC 1.14.99.3) catalyzes the oxidative degradation of heme and has well-known antioxidant properties in mammals by mean of its products biliverdin IX $\alpha$ and carbon monoxide (Kikuchi et al. 2005). We have previously shown that HO-1 is induced in plant tissues as a result of $\mathrm{Cd}$ treatment and confers protection against oxidative stress (Noriega et al. 2004; Balestrasse et al. 2005).Recently, it has been demonstrated that carbon monoxide mitigates salt-induced inhibition of root growth and suppresses programmed cell death in wheat primary roots by inhibiting superoxide anion overproduction (Ling et al. 2009). Moreover, it has been reported that ROS are involved in HO-1 up-regulation in soybean leaves subjected to $\mathrm{Cd}$ treatment (Balestrasse et al. 2006). We hypothesized that SA may also participate in this process, as it regulates the oxidative status and mediates other responses.

The aim of this work was to study the influence of SA on the antioxidant system of soybean plants grown in the presence of $\mathrm{Cd}$, and to find whether oxidative stress tolerance could be the result of HO-1 modulation by exogenous SA thus supplying information on the possible involvement of oxidative stress in the mechanism of damage by $\mathrm{Cd}$.

\section{Materials and methods}

Plant material and growing conditions

Seeds of soybean (Glycine max L., A6445RG) were surface sterilized with $5 \%(\mathrm{v} / \mathrm{v})$ sodium hypochlorite for $10 \mathrm{~min}$ and then washed with distilled water four times and were planted in vermiculite for 5 days. After germination, plants were removed from pots; roots were gently washed and transferred to separated containers for hydroponics. Five liter pots were used, containing six plants each. Plants were germinated and grown in a controlled climate room at $24 \pm 2{ }^{\circ} \mathrm{C}$ and 50 $\%$ relative humidity, with a photoperiod of $16 \mathrm{~h}$ and a light intensity of $175 \mu \mathrm{mol} \mathrm{m} \mathrm{m}^{-2} \mathrm{~s}^{-1}$. The hydroponic medium consisted of Hoagland nutrient solution (Hoagland and Arnon 1950). The medium was continuously aerated $\left(100 \mathrm{ml} \mathrm{min}^{-1}\right)$ and replaced every 3 
days. Plants were pre-treated with different SA concentrations ranging from 0 to $500 \mathrm{mM}$. Afterwards, treatment with $\mathrm{Cl}_{2} \mathrm{Cd}(50 \mu \mathrm{M})$ was performed for 5 days $h$. Leaves were separated and used for determinations. Meausurements were performed by triplicate in three different experiments employing six plants for each treatment.

Thiobarbituric acid reactive substances (TBARS) determination

Lipid peroxidation was measured as the amount of TBARS determined by the thiobarbituric acid (TBA) reaction as described by Heath and Packer (1968). Fresh control and treated leaves $(0.3 \mathrm{~g})$ were homogenized in 3 $\mathrm{ml}$ of $20 \%(\mathrm{w} / \mathrm{v})$ trichloroacetic acid (TCA). The homogenate was centrifuged at 3,500 $\times g$ for $20 \mathrm{~min}$. To 1 $\mathrm{ml}$ of the aliquot of the supernatant, $1 \mathrm{ml}$ of $20 \%$ TCA containing $0.5 \%(\mathrm{w} / \mathrm{v})$ TBA and $1 \mathrm{ml} 4 \%$ butylated hydroxytoluene (BHT) in ethanol were added. The mixture was heated at $95^{\circ} \mathrm{C}$ for $30 \mathrm{~min}$ and then quickly cooled on ice. The contents were centrifuged at $10,000 \times g$ for $15 \mathrm{~min}$ and the absorbance was measured at $532 \mathrm{~nm}$. Value for non-specific absorption at $600 \mathrm{~nm}$ was subtracted. The concentration of TBARS was calculated using an extinction coefficient of $155 \mathrm{mM}^{-1} \mathrm{~cm}^{-1}$.

Glutathione determination

Non-protein thiols were extracted by homogenizing $0.3 \mathrm{~g}$ of leaves in $3.0 \mathrm{ml}$ of $0.1 \mathrm{~N} \mathrm{HCl}(\mathrm{pH} 2.0)$, and $1 \mathrm{~g}$ PVP. After centrifugation at $10,000 \times g$ for $30 \mathrm{~min}$ at 4 ${ }^{\circ} \mathrm{C}$, the supernatants were used for analysis. Total glutathione content (GSH plus GSSG) was determined in the homogenates by spectrophotometry at $412 \mathrm{~nm}$, using yeast-GR, DTNB and NADPH. GSSG was determined by the same method in the presence of 2-vinylpyridine and GSH content was calculated from the difference between the total glutathione content and GSSG content (Anderson 1985).

\section{Chlorophyll determination}

Leaves $(0.5 \mathrm{~g}$, fresh weight $)$ were homogenized with $96 \%$ ethanol $(1: 30 \mathrm{w} / \mathrm{v})$. Extracts were heated in a boiling bath until complete bleaching. After centrifugation, the absorbance was measured in the supernatant at 665, 649 and $654 \mathrm{~nm}$ as described by Wintermans and de Mots (1965).
Superoxide dismutase and catalase assays

Extracts for determination of SOD and CAT activities were prepared from $0.3 \mathrm{~g}$ of leaves homogenized under ice-cold conditions in $3 \mathrm{ml}$ of extraction buffer, containing $50 \mathrm{mM}$ phosphate buffer ( $\mathrm{pH} 7.4), 1 \mathrm{mM}$ EDTA, 1 g PVP, and $0.5 \%$ (v/v) Triton X-100 at $4{ }^{\circ} \mathrm{C}$. The homogenates were centrifuged at $10,000 \times g$ for 20 min and the supernatant fraction was used for the assays.

CAT activity was determined in the homogenates by measuring the decrease in absorption at $240 \mathrm{~nm}$ in a reaction medium containing $50 \mathrm{mM}$ potassium phosphate buffer ( $\mathrm{pH}$ 7.2) and $2 \mathrm{mM} \mathrm{H}_{2} \mathrm{O}_{2}$. The pseudofirst order reaction constant $\left(\mathrm{k}^{\prime}=\mathrm{k}[\mathrm{CAT}]\right)$ of the decrease in $\mathrm{H}_{2} \mathrm{O}_{2}$ absorption was determined and the catalase content in pmol mg ${ }^{-1}$ protein was calculated using $\mathrm{k}=4.7 \times 10^{7} \mathrm{M}^{-1} \mathrm{~s}^{-1}$.

Total SOD activity was assayed by the inhibition of the photochemical reduction of NBT, as described by Becana et al. (1986). The reaction mixture consisted of $50-150 \mu \mathrm{l}$ of enzyme extract and $3.5 \mathrm{ml} \mathrm{O}{ }_{2}^{-}$ generating solution which contained $14.3 \mathrm{mM}$ methionine, $82.5 \mu \mathrm{M}$ NBT, and $2.2 \mu \mathrm{M}$ riboflavin. Extracts were brought to a final volume of $0.3 \mathrm{ml}$ with $50 \mathrm{mM}$ K-phosphate (pH 7.8) and $0.1 \mathrm{mM} \mathrm{Na} 2$ EDTA. Test tubes were shaken and placed $30 \mathrm{~cm}$ from a light bank consisting of six $15 \mathrm{~W}$ fluorescent lamps. The reaction was allowed to run for $10 \mathrm{~min}$ and stopped by switching the light off. The reduction in NBT was followed by reading absorbance at $560 \mathrm{~nm}$. Blanks and controls were run the same way but without illumination and enzyme, respectively. One unit of SOD was defined as amount of enzyme which produced a $50 \%$ inhibition of NBT reduction under the described assay conditions.

GPOX activity was determined in the homogenates by measuring the increase in absorption at $470 \mathrm{~nm}$ due to the formation of tetraguaiacol (e: $26.6 \mathrm{~m} \mathrm{M}^{-1} \mathrm{~cm}^{-1}$ ) in a reaction containing extract, $50 \mathrm{mM} \mathrm{K}$-phosphate buffer $\mathrm{pH} 7,0.1 \mathrm{mM}$ EDTA, $10 \mathrm{mM}$ guaiacol and 10 $\mathrm{mM} \mathrm{H}_{2} \mathrm{O}_{2}$. One unit of GPOX forms $1 \mu \mathrm{mol}$ of oxidised guaiacol per minute under the assay conditions.

Histochemical analysis

To analyze $\mathrm{H}_{2} \mathrm{O}_{2}$ generation leaves were excised and immersed in a $1 \%$ solution of 3,3'-diaminobenzidine 
(DAB) in Tris-HCl buffer ( $\mathrm{pH}$ 6.5), vacuum-infiltrated for $5 \mathrm{~min}$ and then incubated at room temperature for $16 \mathrm{~h}$ in the absence of light. Roots were illuminated until appearance of brown colors characteristic of the reaction of DAB with $\mathrm{H}_{2} \mathrm{O}_{2}$.

In the same way to show $\mathrm{O}_{2}{ }^{-}$production roots were excised and immersed in a $0.1 \%$ solution of NBT in K-phosphate buffer (pH 6.4), containing $10 \mathrm{mM}$ $\mathrm{Na}$-azide, and were vacuum-infiltrated for $5 \mathrm{~min}$ and illuminated until appearance of dark spots, characteristic of blue formazan precipitate.

Heme oxygenase preparation and assay

Leaves $(0.3 \mathrm{~g})$ were homogenized in a Potter-Elvehejm homogenizer using $4 \mathrm{vol}$ of ice-cold $0.25 \mathrm{M}$ sucrose solution containing $1 \mathrm{mM}$ phenylmethyl sulfonyl fluoride, $0.2 \mathrm{mM}$ EDTA and $50 \mathrm{mM}$ potassium phosphate buffer ( $\mathrm{pH}$ 7.4). Homogenates were centrifuged at $20,000 \times g$ for $20 \mathrm{~min}$ and supernatant fractions were used for activity determination. Heme oxygenase activity was determined as previously described with minor modifications (Muramoto et al. 2002). The standard incubation mixture in a final volume of $500 \mathrm{ml}$ contained $10 \mathrm{mmol}$ potassium phosphate buffer ( $\mathrm{pH} 7.4$ ), $60 \mathrm{nmol} \mathrm{NADPH}, 250 \mathrm{ml}$ $\mathrm{HO}(0.5 \mathrm{mg}$ protein), and $200 \mathrm{nmol}$ hemin. Incubations were carried out at $37^{\circ} \mathrm{C}$ during $60 \mathrm{~min}$. Activity was determined by measuring biliverdin formation, which was calculated using the absorbance change at $650 \mathrm{~nm}$ employing an 1 value of $6.25 \mathrm{mM}^{-1} \mathrm{~cm}^{-1}$ (vis $\max 650 \mathrm{~nm}$ ).

\section{Western-blots analysis for $\mathrm{HO}$ protein}

Proteins from leaves were subjected to denaturing SDS-PAGE in a Mini-PROTEAN 3 System (Bio-Rad Laboratories, California). SDS-PAGE was performed in $12 \%$ gels for HO (4\% stacking gels), respectively and run according to Laemmli (1970). The separated polypeptides were transferred to a nitrocellulose membrane at $25 \mathrm{~V} / 300 \mathrm{~mA}$ for $2 \mathrm{~h}$ in a Mini-TransBlot Electrophoretic System (Bio-Rad Laboratories, California) according to the manufacturer's instructions. The membranes were washed in $25 \mathrm{mM}$ Tris$\mathrm{HCl}(\mathrm{pH}$ 8.5), $192 \mathrm{mM}$ glycine and $20 \%(\mathrm{v} / \mathrm{v})$ methanol. The blots were blocked by incubation for 2 $\mathrm{h}$ in $2 \%(\mathrm{w} / \mathrm{v})$ powdered non-fat dry milk dissolved in T-TBS (20 mM Tris- $\mathrm{HCl}$ at $\mathrm{pH} 7.6,137 \mathrm{mM} \mathrm{NaCl}$ and $0.1 \%(\mathrm{v} / \mathrm{v})$ Tween 20 before reaction with an appropriate antibody. The membrane was incubated with rabbit antibody A. thaliana HO-1 (dilution 1:2,000) (Muramoto et al. 1999). The antibody for HO-1 was diluted in T-TBS with $2 \%$ (w/v) powdered non-fat dry milk and were washed twice for $10 \mathrm{~min}$ each with T-TBS. Goat anti-rabbit horseradish peroxidase conjugate was used as a secondary antibody and incubated for $1 \mathrm{~h}$. The blots were washed twice for 10 min before color development (ECL immunodetection system, ECL Western Blotting protocols, Dako). The intensity of bands was analyzed with Gel-Pro Analyzer 3.1 software (Media Cybernetics, MD, USA). The films were scanned (Fotodyne Incorporated, WI, USA) and analysed using Gel-Pro Analyzer 3.1 software (Media Cybernetics, MD, USA).

\section{Cadmium determination}

Segments from the second pair of fully expanded leaves upper the cotyledons with or without $\mathrm{Cd}$ addition were thoroughly rinsed to eliminate the metal that could be superficially adsorbed. Plant material was dried at $80^{\circ} \mathrm{C}$ during $48 \mathrm{~h}$, weighed and ground to a fine powder. $\mathrm{Cd}$ determinations were made digestion in $\mathrm{HNO}: \mathrm{HClO}(3: 1, \mathrm{v} / \mathrm{v})$ by atomic absorption spectrophotometry (Perkin-Elmer, Analyst 300).

Protein determination

Protein concentration was evaluated by the method of Bradford (1976), using bovine serum albumin as a standard.

\section{Results}

Lipid peroxidation

Oxidative stress was assessed by measuring lipid peroxidation rate when soybean plants were exposed to $50 \mu \mathrm{M} \mathrm{Cd}$ and to SA (0-500 mM) (Fig. 1). On one hand, TBARS content was significantly enhanced in plants treated with $\mathrm{Cd}$ (100\% respect to controls). On the other hand, only $500 \mathrm{mM} \mathrm{SA}$ increased $43 \%$ 
Fig. 1 a Effect of Cd and SA on soybean leaves TBARS formation. $\mathbf{b}$ Effect of SA pre-treatment before $\mathrm{Cd}$ addition on soybean leaves TBARS formation. Experiments were performed as described in "Materials and Methods" section. Different letters within columns indicate significant differences $(\mathrm{P}<0.05)$
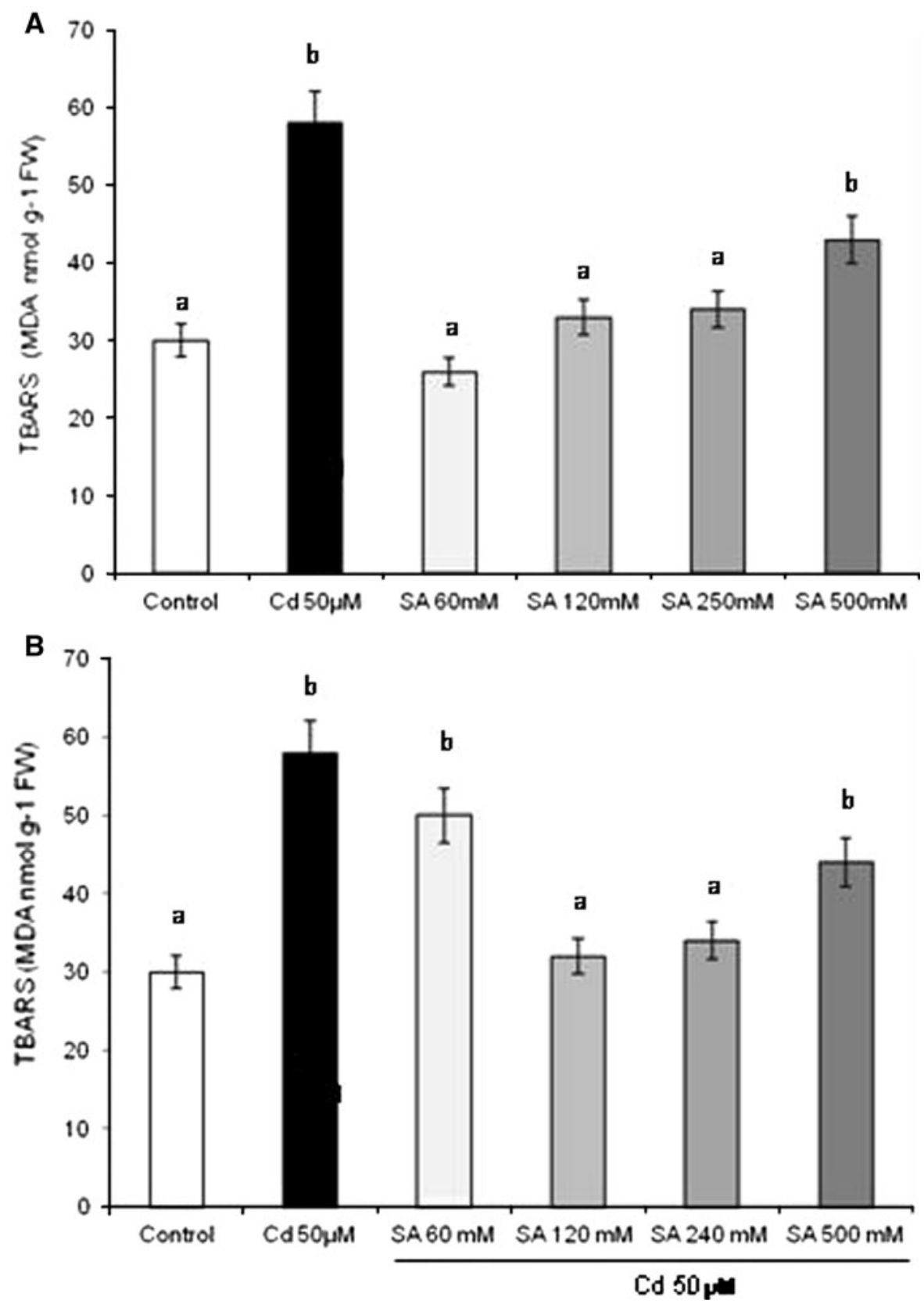

RBARS content respect to controls. Lower concentrations did not produce any changes respect to controls. In order to know whether pre-treatment with SA could prevent lipid peroxidation caused by $\mathrm{Cd}$, experiments were carried out employing different SA acid concentrations ranging from 0 to $500 \mathrm{mM}$. Figure $1 \mathrm{~b}$ shows that $120 \mathrm{mM}$ SA completely abolished TBARS enhancement brought about by $\mathrm{Cd}$, but it did not alter any other parameter As a consequence 120 mM SA was chosen for further experiments.

Reactive oxidative species production

Cadmium application resulted in ROS accumulation as observed in Fig. 2. Salicylic acid pre-treatment partially abolished $\mathrm{O}_{2}{ }^{-}$as well as $\mathrm{H}_{2} \mathrm{O}_{2}$ formation. 




Control
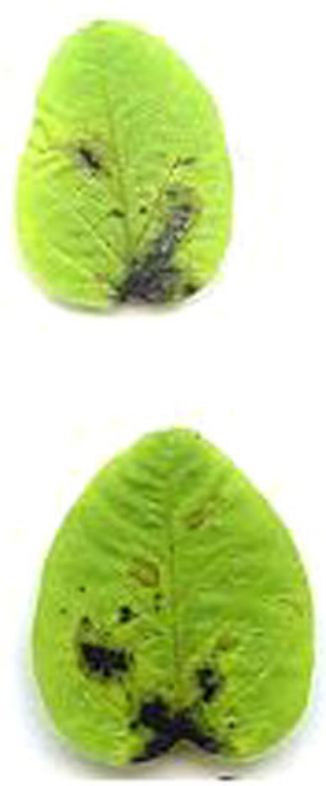

Cd 50 uM
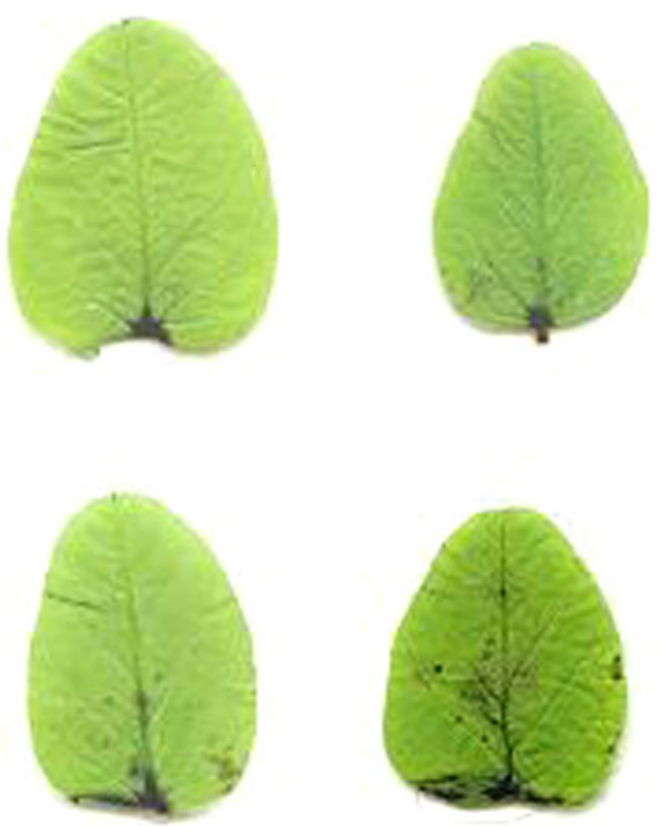

$\mathrm{SA} 120 \mathrm{mM}$

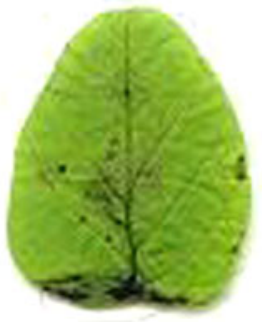

$S A 120 m M+C d 50 u M$

Fig. $2 \mathrm{H}_{2} \mathrm{O}_{2}$ and $\mathrm{O}_{2}{ }^{-}$localization in situ. Experiments were performed as described in "Materials and Methods" section

Table 1 Effect of Cd and SA pre-treatment on soybean leaves antioxidant enzyme activities

\begin{tabular}{llcl}
\hline Treatment & SOD (U/mg protein) & CAT (pmol/mg protein) & GPOX (U/mg protein) \\
\hline Control & $19.5 \pm 0.5^{\mathrm{a}}$ & $150 \pm 8^{\mathrm{a}}$ & $0.043 \pm 0.001^{\mathrm{a}}$ \\
Cd $50 \mu \mathrm{M}$ & $10.4 \pm 0.7^{\mathrm{b}}$ & $50 \pm 15^{\mathrm{b}}$ & $0.024 \pm 0.001^{\mathrm{b}}$ \\
$120 \mathrm{mM} \mathrm{SA}$ & $18.9 \pm 0.6^{\mathrm{a}}$ & $187 \pm 6^{\mathrm{c}}$ & $0.045 \pm 0.001^{\mathrm{a}}$ \\
$120 \mathrm{mM} \mathrm{SA}+\mathrm{Cd} 50 \mu \mathrm{M}$ & $21.2 \pm 0.5^{\mathrm{a}}$ & $140 \pm 14^{\mathrm{a}}$ & $0.039 \pm 0.001^{\mathrm{a}}$
\end{tabular}

Enzymatic activities were assayed as described in the experimental section. Different letters within columns indicate significant differences $(P<0.05)$ according to Tukey's multiple range test

\section{Antioxidant enzymes}

Cadmium inhibited $46 \%$ in SOD activity respect to controls and SA had no effect on this parameter. On the other hand, plants subjected to SA previously to $\mathrm{Cd}$ addition did not show any changes respect to controls (Table 1).

Catalase activity was diminished by $\mathrm{Cd}(47 \%)$ and an increase $(25 \%)$ was observed in SA-treated plants respect to controls. Moreover, pretreatment with SA before $\mathrm{Cd}$ addition avoided the inhibition previously observed in the presence of Cd (Table 1). When GPOX activity was analyzed, an inhibition was observed under Cd treatment (45\%) and SA alone did not cause any changes respect to controls. Salicylic acid pretreatment totally avoided $\mathrm{Cd}$ inhibition.

Chlorophyll content

Chlorophyll can be bleached under oxidative stress. Figure 3 shows that chlorophyll content was markedly decreased under $\mathrm{Cd}$ treatment $(71 \%$ respects to controls). Experiments carried out in the presence of SA revealed that this hormone partially protects against chlorophyll loss against $\mathrm{Cd}$ insult $(20 \%)$. On the other hand, SA alone had no effect on this parameter. 


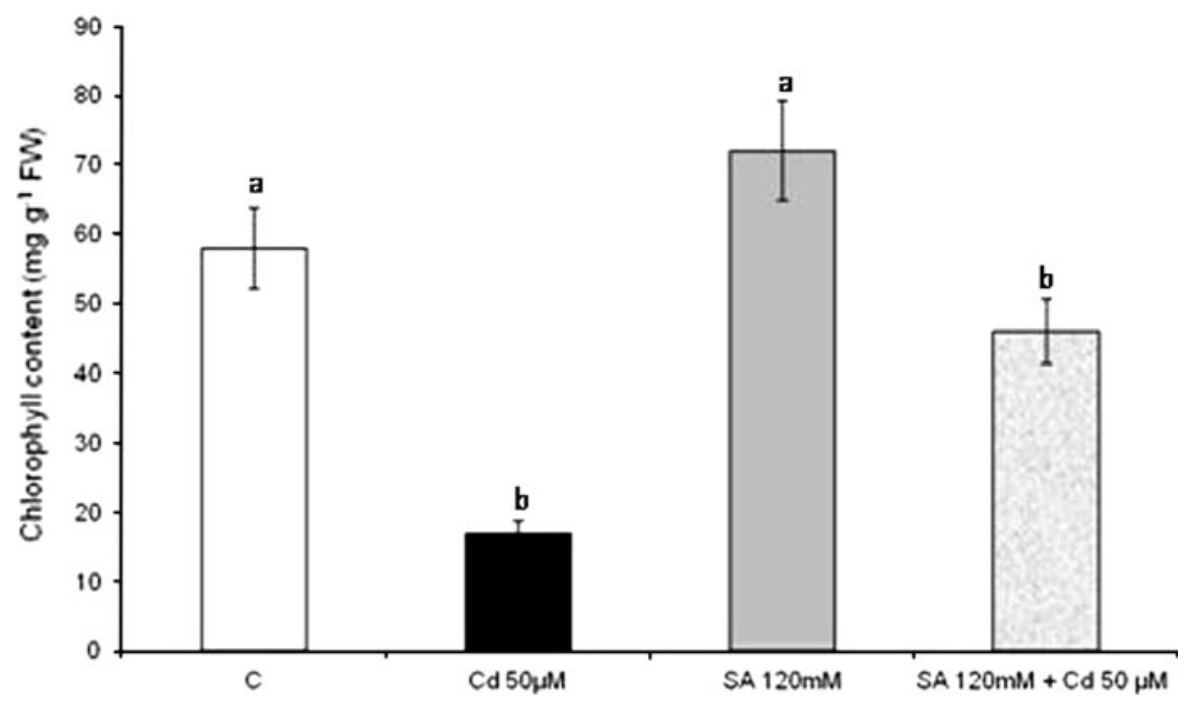

Fig. 3 Effect of Cd and SA pre-treatment on soybean leaves chlorophyll content. Experiments were performed as described in "Materials and Methods" section. Different letters within columns indicate significant differences $(P<0.05)$

Fig. 4 Effect of Cd and SA pre-treatment on soybean leaves GSH content. Experiments were performed as described in "Materials and Methods" section. Different letters within columns indicate significant differences $(P<0.05)$

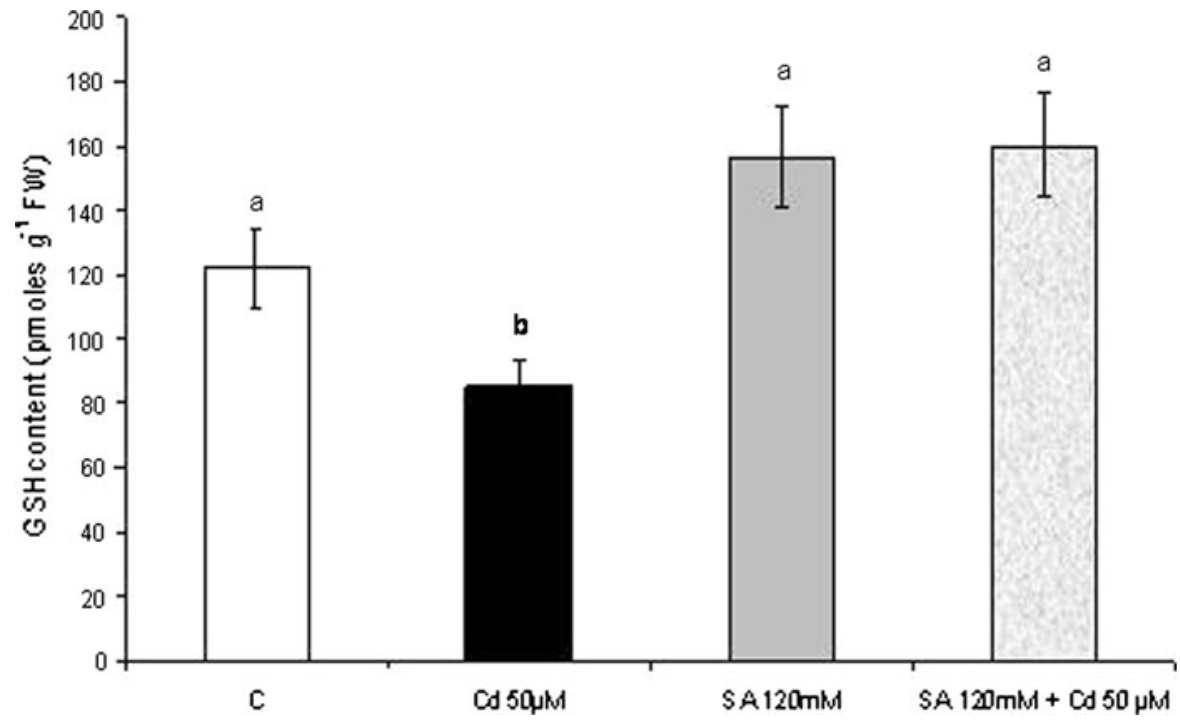

\section{Glutathione levels}

Glutathione content was determined as a non enzymatic defense. Figure 4 shows a $30 \%$ diminution in GSH content respect to controls in Cd treated plants. Experiments carried out in the presence of SA indicated that no changes have occurred respect to controls. On the other hand, a protection against GSH loss was also observed in plants pretreated with SA before $\mathrm{Cd}$ addition.

\section{Heme oxygenase}

We have previously reported that $\mathrm{Cd}$ treatment results in an increase of HO-1 activity in soybean roots nodules (Balestrasse et al. 2005). To further characterize this induction, here we analyze HO-1 activities in leaves in response to $50 \mu \mathrm{M} \mathrm{Cd}$ in the presence and absence of $120 \mu \mathrm{M}$ SA. Figure 5a shows that in the presence of 50 $\mu \mathrm{M} \mathrm{Cd}$ a $57 \%$ increase in HO-1 activity occurred, respect to controls. Salicylic acid alone also increases, 
Fig. 5 Effect of Cd and SA pre-treatment on soybean leaves $\mathrm{HO}$ activity (a) and protein amount (b). Data are means of three independent experiments and bars indicate SE. Different letters within columns indicate significant differences $(P<0.05)$.Experiments were performed as described in "Materials and Methods" section

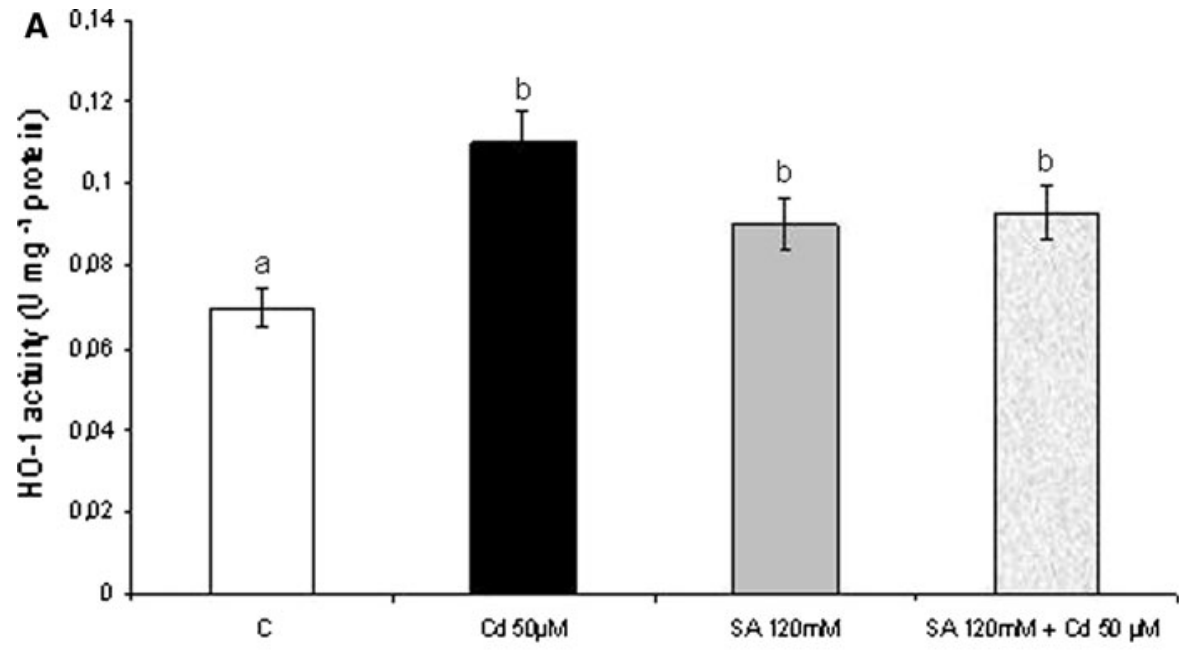

B HO-1


$32 \mathrm{KDa}$

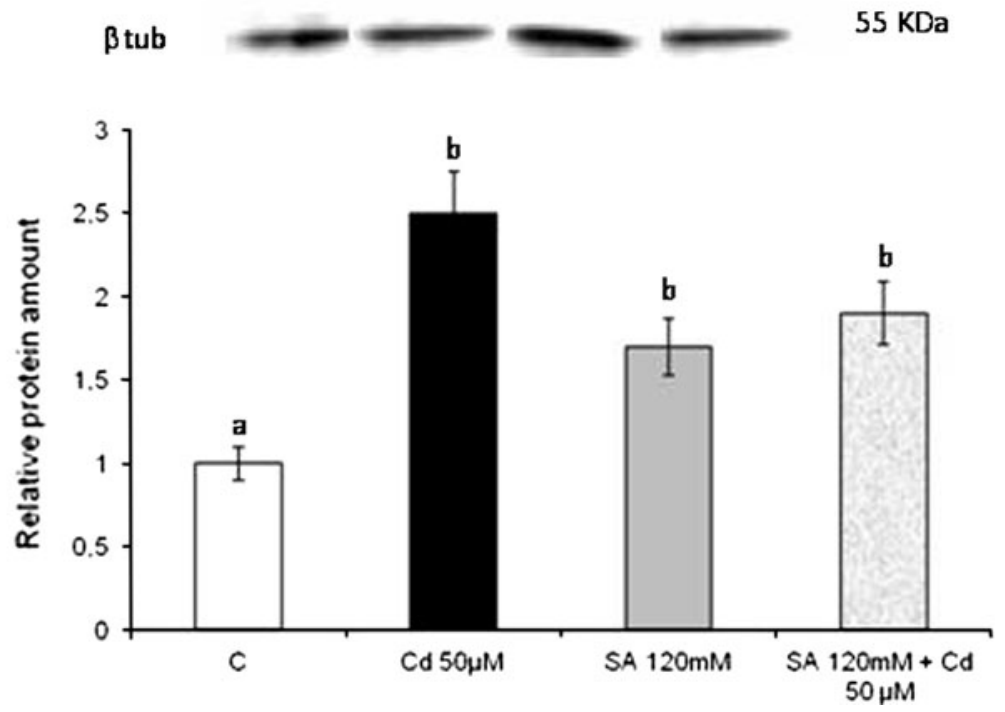

but only $28 \%$ enzyme activity respect to controls. The same result was obtained in plants pre-treated with SA before $\mathrm{Cd}$ addition. On the other hand, western blott analysis Fig. $5 \mathrm{~b}$ revealed a positive relationship between enzyme activity and protein content. Plants treated with SA also showed an increase in HO-1 protein content (75 $\%)$ respect to controls. When this analysis was carried out in plants treated with SA before $\mathrm{Cd}$ addition, once again an enhancement (by about $78 \%$ ) was detected.
Cadmium determination

Cadmium determinations were performed by atomic absorption spectrometry in an attempt to elucidate whether SA could have any effect on its uptake. Table 2 shows that in the presence of $120 \mu \mathrm{M}$ SA Cd uptake was diminished compared with values obtained with $\mathrm{Cd}$ was added alone. Cd content was not detected in the presence of $120 \mu \mathrm{M} \mathrm{SA}$ alone. 
Table 2 Effect of SA pre-treatment on Cd content in soybean leaves

\begin{tabular}{ll}
\hline Treatment & Cadmium content $(\mathrm{mg} / \mathrm{g} \mathrm{FW})$ \\
\hline Control & $0.002 \pm 0.001^{\mathrm{a}}$ \\
$\mathrm{Cd} 50 \mu \mathrm{M}$ & $0.029 \pm 0.008^{\mathrm{b}}$ \\
$120 \mathrm{mM} \mathrm{SA}$ & $\mathrm{ND}$ \\
$120 \mathrm{mM} \mathrm{SA}+\mathrm{Cd} 50 \mu \mathrm{M}$ & $0.008 \pm 0.001^{\mathrm{c}}$ \\
\hline
\end{tabular}

Enzymatic activities were assayed as described in the experimental section. Different letters within columns indicate significant differences $(P<0.05)$ according to Tukey's multiple range test

\section{Discussion and conclusions}

Elevated TBARS content, ROS accumulation and chlorophyll loss are regarded as sensitive indicators of heavy metals toxicity in plants and their measurements have been proposed as bioassays for identifying plants exposed to metals, including Cd (Popova et al. 2009).

Data here reported, indicate that $\mathrm{Cd}$ treatment induced oxidative stress and production of $\operatorname{ROS}\left(\mathrm{H}_{2} \mathrm{O}_{2}\right.$ and $\mathrm{O}_{2}{ }^{-}$) as well as enhanced TBRS content, decreased GSH levels and activity of antioxidant enzymes such as SOD, CAT and GPOX, and also enhanced HO-1 activity and its protein content.

To cope with Cd toxicity, plants can make use of several defense strategies, including phytochelation and sequestration as well as the induction of antioxidant machinery and stress proteins (Cobbett and Goldsbrough 2002; Vázquez et al. 2006). In the case of metals toxicity, in particular $\mathrm{Cd}$, plants have developed other detoxification mechanisms related with some stress signalling molecules, such as SA and NO (Rodriguez-Serrano et al. 2006). Salicylic acid is considered as a hormone-like substance, which plays an important role in regulating a number of physiological processes and plant resistance to biotic and abiotic stresses (Mishra and Chudhuri 1999).

Data here reported, do indicate that SA protects against the deleterious effects produced by $\mathrm{Cd}$.

This phytohorme, is also involved in ion uptake and transport (Ray 1986). There are evidence that SA ameliorates the damaging effects of heavy metals by broad but different effects (Drazic and Mihailovic 2005; Metwally et al. 2003; Mishra and Chudhuri 1999). Salicylic acid pre-treatment alleviated Cd toxicity in barley and maize plants (Metwally et al. 2003). The protective function of SA includes regulation of ROS and antioxidants, induction of gene expression (Shah 2003), and absorption and distribution of elements (Metwally et al. 2003, Mishra and Chudhuri 1999).

However, the role of exogenously applied SA under $\mathrm{Cd}$ stress in plants is not yet clear and needs further investigations.

Based on the above studies, our aim was to examine the possible interaction between SA and HO-1 in plants exposed to $\mathrm{Cd}$.

Data here reported showed that SA enhanced both HO-1 activity and its protein content compared with controls, and that these increments were lower than those produced by $\mathrm{Cd}$ alone. Unexpectedly, this behaviour was also observed in plants treated with both SA and Cd. These results prompted us to evaluate $\mathrm{Cd}$ content in the leaves. Data obtained, indicated that $\mathrm{Cd}$ uptake is reduced in the presence of SA and let us conclude that its protective effect is not due to its action on HO-1 as it happens with another phytohormone tested such as jasmonic acid (Noriega et al. 2012), but as a result of a lower Cd content in the leaves.

It has been already reported that a moderate resistance to heavy metals can occur by selective $\mathrm{Cd}$ exclusion, diminished uptake, or active efflux from the roots, i.e. by mechanisms leading to lower cytoplasmic Cd content (Hall 2002). It is interesting to note, that on one hand, SA inhibits Cd uptake and on the other hand, SA alone enhanced both HO-1 activity and its protein content, as well as increased by $25 \%$ CAT activity, but it did not alter any of the other oxidative stress parameters here assayed This particular behaviour could prepare the tissue to protect itself against a possible aggression and this is the reason why a concomitantly up-regulation of HO-1 and CAT gene expression was also found in soybean nodules subjected to high Cd stress (Balestrasse et al. 2008).

All together these findings are indicating that in the presence of another stressing factor, which could be transported into the cells, SA could exert its protective effect through HO-1. We have found that soybean plants treated with ZnPPIX, an irreversible HO-1 inhibitor, are prone to oxidative damage (Noriega et al. 2004; Balestrasse et al. 2005).

In this paper we have found good evidence that SA can exert a significant beneficial effect on Cd exposed soybean plants. Interestingly, increased antioxidant defense appears not to be involved in the alleviation of 
Cd toxicity, because SA itself inhibited Cd accumulation in the leaves. These data contrast with our own previously reported results about jasmonic acid, another phytohormone, which protected soybean plants against $\mathrm{Cd}$ induced oxidative stress, by enhancing HO-1 activity and its expression. (Noriega et al. 2012).

Taken together, data reported herewith suggested that SA could prevent $\mathrm{Cd}$-induced oxidative damage, which might be due to a diminished metal uptake. Nevertheless, it should be recalled that although SA inhibited Cd transport, it also enhanced per se HO-1 activity and its protein content as well as increased CAT activity, that could eventually prevent oxidative stress provoked by other stressing factors.

In other words, SA not only can inhibit Cd transport but it can also prevent oxidative stress by modifying the antioxidant defense system, whenever necessary.

\section{References}

Anderson ME (1985) Determination of glutathione and glutathione disulfide in biological samples. Methods Enzymol 113:548-554

Balestrasse KB, Noriega GO, Batlle A, Tomaro ML (2005) Involvement of heme oxygenase as antioxidant defense in soybean nodules. Free Radic Res 39:145-151

Balestrasse KB, Noriega GO, Batlle A, Tomaro ML (2006) Heme oxigenase activity and stress signaling in soybean leaves. Plant Sci 170(2):339-346

Balestrasse KB, Yannarelli GG, Noriega GO, Batlle A, Tomaro M (2008) Heme oxygenase and catalase gene expression in nodules and roots of soybean plants subjected to cadmium stress. Biometals 21(4):433-441

Becana M, Aparicio-Tejo P, Irigoyen J, Sánchez-Díaz M (1986) Some enzymes of hydrogen peroxide metabolism in leaves and root nodules of Medicago sativa. Plant Physiol 82:1169-1171

Bradford M (1976) A rapid and sensitive method for the quantitation of microgram quantities of protein utilizing the principle of protein-dye binding. Anal Biochem 72: 248-254

Cobbett C, Goldsbrough P (2002) Phytochelatins and metallothioneins: role of heavy metal detoxication and homeostasis. Annu Rev Plant Biol 53:159-182

Dat J, Foyer C, Scott M (1998) Changes in salicylic acid and antioxidants during induced thermotolerance in mustard seedlings. Plant Physiol 118:1455-1461

Drazic G, Mihailovic N (2005) Modification of cadmium toxicity in soybean seedlings by salicylic acid. Plant Sci 168(2):511-517

Durner J, Klessig DF, Shah J (1997) Salicylic acid and disease resistance in plants. Trends Plant Sci 2:266-274
Foyer CH, Descourvieres P, Kunert KJ (1994) Protection against oxygen radicals: an important defence mechanism studied in transgenic plants. Plant Cell Environ 17: 507-523

Gunes A, Inal A, Alpaslam M, Erslan F, Bagsi E, Cicek N (2007) Salicylic acid induced changes on some physiological parameters symptomatic for oxidative stress and mineral nutrition in maize (Zea mays L.) grown under salinity. J Plant Physiol 164:728-736

Hall JL (2002) Cellular mechanisms for heavy metal detoxification and tolerance. J Exp Bot 53:1-11

Hayat S, Ali B, Ahmad A (2007) Salicylic acid: biosynthesis, metabolism and physiological role in plants. In: Hayat $S$, Ahmad A (eds) Salicylic acid: a plant hormone. Springer, Drodrecht, pp 1-14

Heath RL, Packer L (1968) Photoperoxidation in isolated chloroplasts. Kinetics and stoichiometry of fatty acid peroxidation. Arch Biochem Biophys 125:189-198

Hoagland DR, Arnon DI (1950) The water-culture method for growing plants without soil. University of California, the Agricultural Experiment Station. Berkley Circ 347:1-39

Horváth E, Szalai G, Janda T (2007) Induction of a biotic stress tolerance by salicylic acid signaling. J Plant Growth Regul 26:290-300

Järup L, Ảkesson A (2009) Current status of cadmium as an environmental health problem. Toxicol Appl Pharmacol 238:201-208

Kang H, Saltveit M (2002) Chilling tolerance of maize, cucumber, and rice seedling leaves and roots are differentially affected by salicylic acid. Physiol Plant 115: 571-576

Kikuchi G, Yoshida T, Noguchi M (2005) Heme oxygenase and heme degradation. Biochem Biophys Res Commun 338:558-567

Krantev A, Yordanova R, Janda T, Szalai G, Popova L (2008) Treatment with salicylic acid decreases the effect of cadmium on photosynthesis in maize plants. J Plant Physiol 165:920-931

Laemmli UK (1970) Cleavage of structural proteins during the assembly of the head of bacteriophage T4. Nature 227: 680-685

Ling T, Zhang B, Cui W, Wu M, Lin J, Zhou W, Huang J, Shen W (2009) Carbon monoxide mitigates salt-induced inhibition of root growth and suppresses programmed cell death in wheat primary roots by inhibiting superoxide anion overproduction. Plant Sci 177:331-340

Malamy J, Carr J, Klessig D, Raskin I (1990) Salicylic acid a likely endogenous signal in the resistance response of tobacco to viral infection. Science 250:1002

Mc Laughlin M, Parker D, Clarke J (1999) Metal and micronutrients-food safety issues. Field Crop Res 60:143-163

Metwally A, Finkermeier I, Georg M, Dietz J (2003) Salicylic acid alleviates the cadmium toxicity in barley seedlings. Plant Physiol 132:272-281

Mishra A, Chudhuri M (1999) Effect of salicylic acid on heavy metal-induced membrane deterioration in rice. Biol Plant 42:409-415

Muramoto T, Kohchi T, Yokota A, Hwang T, Goodman H (1999) The Arabidopsis photomorphogenic mutant hyl is deficient in phytochrome chromophore biosynthesis as a 
result of a mutation in a plastid heme oxygenase. Plant Cell 11:335-348

Muramoto T, Tsurui N, Terry M, Yokota A, Kohchi T (2002) Expression and biochemical properties of a ferredoxindependent heme oxygenase required for phytochrome chromophore synthesis. Plant Physiol 130:1958-1966

Noriega GO, Balestrasse KB, Batlle A, Tomaro ML (2004) Heme oxygenase exerts a protective role against oxidative stress in soybean leaves. Biochem Biophys Res Commun 323:1003-1008

Noriega GO, Santa Cruz DM, Batlle A, Tomaro ML, Balestrasse KB (2012) Heme oxygenase is involved in the protection exerted by jasmonic acid against cadmium stress in soybean roots. J Plant Growth Regul 31(1):79-89

Popova LP, Maslenkova LT, Yordanova RY, Ivanova AP, Krantev AP, Szalai G, Janda T (2009) Exogenous treatment with salicylic acid attenuates cadmium toxicity in pea seedlings. Plant Physiol Biochem 47:224-231

Ray S (1986) GA, ABA, phenol interaction in the control of growth: phenolic compounds as effective modulators of GA-ABA interaction in radish seedlings. Biol Plant 28: 361-369

Rodriguez-Serrano M, Romero-Puertas M, Zabalza A, Corpas F, Gomez M, Del Rio L, Sandalio L (2006) Cadmium effect on oxidative metabolism of pea (Pisum sativum L.) roots. Imaging of reactive oxygen species and nitric oxide accumulation in vivo. Plant Cell Environ 29:1532-1544

Schutzendubel A, Schwanz P, Teichmann T, Gross K, Langenfeld Heyser R, Godbold DL, Polle A (2001) Cadmium-induced changes in antioxidative systems, hydrogen per oxide content, and differentiation in scot pine roots. Plant Physiol 127:887-889

Shah J (2003) The salicylic acid loop in plant defence. Curr Opin Plant Bio 16:365-371

Vázquez S, Goldsbrough P, Carpena R (2006) Assessing the relative contributions of phytochelatins and the cell wall to cadmium resistance in white lupin. Physiol Plantarum 128: 487-495

Wagner G (1993) Accumulation of cadmium in crop plants and its consequences to human health. Adv Agron 51:173-212

Wang C, Zhang Songhe, PeiFang W, Jun H, Jin Q, Yanhui A, Jie L, Li L (2011) Salicylic acid involved in the regulation of nutrient elements uptake and oxidative stress in Vallisneria natans (Lour.) Hara under $\mathrm{Pb}$ stress. Chemosphere 84: 136-142

Wintermans J, de Mots A (1965) Spectrophotometric characteristics of chlorophylls a and $\mathrm{b}$ and their pheophytins in ethanol. Biochim Biophys Acta 109:448-453 